\title{
Análise de provas elaboradas por professores de inglês da escola pública ${ }^{1}$
}

Maria Tereza Nunes Marchezan

Universidade Federal de Santa Maria

Esta pesquisa foi desenvolvida com o objetivo de descrever provas elaboradas por professores de inglês de escola pública. Constituíram a base dos dados da pesquisa 40 provas elaboradas por professoras de inglês do ensino fundamental. As provas foram analisadas tomando como base os trabalhos de Genesee e Upshur (1998), Bachman e Palmer (1996). As conclusões indicam que: a) quanto aos conteúdos avaliados, o foco das provas concentra-se predominantemente em itens gramaticais, no vocabulário e na estrutura da oração simples e b) quanto às técnicas, há o predomínio de questões de resposta limitada, mais fáceis de elaborar e corrigir, e que exigem pouco conhecimento lingüístico do professor.

This research was developed with the objective of describing tests prepared by teachers of English at the Elementary School. Forty tests prepared by four teachers were the main research data. For the description and analysis of the tests, Genesee and Upshur (1998)'s work was taken as a basis. The conclusions indicate that: a) concerning the contents, tests concentrate mainly on grammar, on vocabulary, and on the structure of simple sentences and b) concerning the techniques, there is a predominance of techniques that require limited answers, easier to both prepare and correct, which require little linguistic knowledge from the teacher.

O professor tem sido alvo de críticas por fazer uso da avaliação como instrumento de poder e de autoritarismo e por reduzir a avaliação à simples atribuição de notas e conceitos, e à idéia de aprovação e reprovação. No entanto, pela própria atribuição inerente à profissão de professor de verificar se houve sucesso nos processos de ensino e aprendizagem e de informar sobre esses processos ao aluno e à sociedade, a avaliação é instrumento de poder em sua mão. É do professor a atribuição de chegar a um resultado fidedigno da avaliação do processo de ensino/ aprendizagem e de divulgá-lo.

\footnotetext{
${ }^{1}$ Este trabalho foi extraído da tese de doutorado Perfil de provas elaboradas por professores de inglês na escola Pública Fundamental.
} 
Sob a perspectiva do aluno, esses resultados são de extrema importância: decidem se o aluno vai ser aprovado ou reprovado, premiado ou punido na escola, em casa e na sociedade. Isso justifica a necessidade de que o processo desenvolvido pelo professor seja claro e apresente características de validade e confiabilidade.

A motivação para o desenvolvimento desta pesquisa é fruto de questionamentos sobre a situação da avaliação de línguas estrangeiras na escola pública do interior do Estado do Rio Grande do Sul, quanto à qualidade dos instrumentos de avaliação que os professores estão utilizando, com foco no tipo de questões e técnicas utilizadas na elaboracão de provas. Este artigo apresenta o resultado de uma pesquisa sobre o perfil das provas elaboradas por professores de inglês do Ensino Fundamental de uma escola do interior do Rio Grande do Sul. A primeira parte constitui o referencial teórico que dá suporte à discussão dos dados. A segunda parte apresenta a metodologia adotada para desenvolver o trabalho. Na terceira parte são discutidos os resultados e, por fim, são apresentadas as conclusões.

\section{Revisão bibliográfica}

Dentre os instrumentos para a avaliação da aprendizagem no Brasil, a prova é o mais utilizado nas escolas (HOFFMAN, 1993; LUCKESI, 1996; ROLIM, 1998; SANTOS, 2002; VASCONCELOS, 2003). Genesee e Upshur (1999) entendem uma prova como um método de coleta de informações e é sempre sobre alguma coisa: inteligência, história da Europa. Em educação, o termo usado para essa "alguma coisa" é conteúdo. O conteúdo de um prova de língua estrangeira é formado pelo conhecimento, as habilidades lingüísticas, o uso da língua. Uma prova constitui-se de atividades para eliciar o comportamento observável do aluno e pode testar apenas uma ou mais de uma habilidade, e um tipo ou mais de um tipo de conhecimento. Por fim, as provas produzem notas que representam atributos, características das pessoas.

Com base nesses autores e no que se observa nas escolas gaúchas, neste trabalho, prova é entendida como um instrumento de coleta de informações sobre o conhecimento/habilidades dos alunos relativos ao conteúdo de ensino, que é planejado pelos professores para ser resolvido em um momento específico do processo de ensino/aprendizagem e que deve resultar em uma nota. 
As provas em estudo foram analisadas, num primeiro momento, quanto ao tipo de questão: objetivas vs. subjetivas e questões de comprensão vs. producão. Na seqüência, foram analisadas quanto às tecnicas utilizadas na elaboração das questões.

\section{Questões objetivas e subjetivas}

As questões de correção objetiva são elaboradas para ter uma única resposta e podem ser corrigidas com base em uma chave de respostas, o que lhes garante confiabilidade. O critério de correção é certo ou errado, o que exclui qualquer julgamento por parte do "corretor" da prova. A elaboração, no entanto, é subjetiva, porque dependem da decisão do professor a técnica da questão (V/F, múltipla escolha, preencher lacunas) e as alternativas e distratores que compõem cada questão, da mesma forma que é o professor quem decide o conteúdo lingüístico que dá base à prova.

Já as questões subjetivas, por sua natureza, requerem um tipo de correção em que são necessários julgamentos de valor sobre os textos produzidos pelos alunos. É o caso de traduções e redações, que, por outro lado, apresentam a vantagem de avaliar as habilidades do aluno mais naturalmente. A correção dessas questões, no entanto, apresenta problema para muitos professores porque demanda muito tempo, pois são produções difíceis de avaliar. As questões integrativas, por não admitirem correção objetiva, são entendidas como subjetivas e vulneráveis à correção e, portanto, com probabilidade de baixa confiabilidade (BAILEY, 1998, p. 78).

\section{Questões de compreensão e produção}

As habilidades de ler, escrever, ouvir e falar podem ser caracterizadas de acordo com a participação do aluno na resolução das questões. As habilidades de compreensão são também referidas como atividades de reconhecimento e as de produção, como atividades de recordação (MEDEIROS, 1971; READ, 2000). As atividades de reconhecimento exigem do aluno memorização e resgate de informação: o aluno deve mostrar que entende os significados. As questões de recordação o "provocam" com algum tipo de estímulo para que ele resgate da memória a informação requerida.

Read (2000), no que se refere a vocabulário, apresenta outra perspectiva para a distinção: recepção x produção, compreensão x uso. Compreensão 
significa que o aluno pode entender o que lê ou ouve no seu contexto de ocorrência. Uso significa que um termo que ocorre em sua fala ou escrita é parte de seu vocabulário ativo. Para avaliar compreensão e uso, as tarefas devem ser contextualizadas.

Essas duas perspectivas dos processos de compreensão e produção refletem duas visões de língua. A primeira, de reconhecimento e recordação, reflete uma visão de tendência estruturalista; a segunda, de compreensão e uso, está associada a uma visão comunicativa da língua.

As provas foram classificadas segundo a técnica utilizada: questões fechadas, questões de resposta limitada e questões de resposta aberta, segundo proposta de Genesse e Upshur (1999). A escolha das técnicas de avaliação ao planejar uma prova é importante, porque cada tipo de questão implica o domínio de uma habilidade para resolvê-la, o que interfere no resultado da prova. Assim, um mesmo conteúdo deve ser abordado por diferentes técnicas.

\section{Questões fechadas}

As questões fechadas apresentam alternativas para que o aluno escolha a resposta. São questões mais adequadas a avaliar as habilidades de compreensão, mas são questões difíceis de redigir. Autores identificados com a abordagem psicométrica-estruturalista, como Lado (1961), Medeiros (1971) e Lindeman (1975), defendem que provas compostas por questões fechadas são suficientes e eficientes para apontar deficiências de aprendizagem. Cabe ressaltar que as questões fechadas, sob ótica comunicativa, não são as mais indicadas para a avaliação da aprendizagem, uma vez que o aluno tem sempre alguma chance de acertar porque a estrutura da questão o permite, o que não demonstra conhecimento (HUGHES, 1989; BAXTER, 1997). Da mesma forma, as questões que o aluno errou não permitem detectar a origem do erro, $\mathrm{O}$ que é muito importante para que o professor possa planejar o retorno adequado no sentindo de (re)orientar a aprendizagem. As questões fechadas são de correção objetiva. São questões fechadas as de múltipla escolha (ME) e de julgamento (V/F e associação). 


\section{Questões de resposta limitada}

As questões de resposta limitada são aquelas que requerem que o aluno pense e elabore sua própria resposta. O professor não apresenta alternativas para que o aluno escolha, embora haja um número limitado de possibilidades de respostas a serem dadas.

São questões mais interessantes do ponto de vista da aprendizagem, à medida que o aluno é solicitado a elaborar uma resposta. Essa característica por si só, no entanto, não garante valor à questão. É muito importante esclarecer ao aluno o que se espera dele, e a redação da ordem da questão deve ser clara e completa, não dando margem a dúvidas. A correção desse tipo de questão requer julgamento da parte do professor, porque as possibilidades de resposta não são únicas: além de correta / incorreta, uma resposta pode ser aceitável / não aceitável, apropriada / não apropriada (GENESEE; UPSHUR, 1999). São questões de resposta limitada: lacunas, questões de ordenamento, ditado, questões de transformação, tradução / versão, responda.

\section{Questões de resposta aberta}

As questões de resposta aberta são questões mais complexas para corrigir porque as respostas dos alunos não são previsíveis. Essas questões são também chamadas subjetivas (MEDEIROS, 1971). Os critérios de correção, da mesma forma que para os outros tipos de questões, devem ser estabelecidos a priori, explicitando-se regras que orientem o professor na correção. Entrevista oral, dramatizações, relatos, redações são exemplos de questões de resposta aberta.

\section{Metodologia}

O trabalho aqui registrado foi desenvolvido em uma escola pública, estadual, localizada no município $\mathrm{M},{ }^{2}$ considerado médio-

\footnotetext{
${ }^{2} \mathrm{O}$ município é referido como $\mathrm{M}$ e a escola como E, para manter em sigilo a identidade das professoras participantes deste trabalho.
} 
pequeno e que, pelo desempenho econômico, ficou entre os 100 melhores do Rio Grande do Sul em 2000 (IBGE, 2000). Localizada no perímetro urbano, a escola $\mathrm{E}$, onde foi desenvolvido o trabalho de pesquisa, é classificada como escola cêntrica, mas atende a alunos de todas as regiões da cidade e da zona rural. Atuam na escola 56 professores, sendo que 35 atendem de $5^{\underline{a}}$ à $8^{\underline{a}}$ séries do ensino regular, dentre os quais 4 são de língua inglesa. A Escola E recebe aproximadamente 1000 alunos, da pré-escola à oitava série. No turno noturno, a escola oferece o programa de Ensino para Jovens e Adultos (EJA) para aproximadamente 150 alunos.

As professoras de inglês concluíram suas licenciaturas em Letras / Inglês em cursos de graduação de instituições de ensino superior, públicas e privadas, da região central do Estado.

As provas, que constituem os dados desta pesquisa, foram elaboradas pelas quatro professoras de inglês da Escola E. Foram analisadas 10 provas de cada professora, o que significa mais de 50\% das provas elaboradas para cada turma, por cada uma das professoras, durante o ano de 2004.

A seleção dessas provas obedeceu ao seguinte critério: a) que as provas tivessem sido elaboradas pelas próprias professoras, isto é, que não fossem planejadas por outros; b) que, de cada prova selecionada, estivessem disponíveis exemplares resolvidos e corrigidos pela professora, para esclarecer sobre o planejamento e objetivos que não pudessem ser detectados pela prova proposta, nem suficientemente esclarecidos nas entrevistas ${ }^{3}$ e c) que, pelo menos, duas dessas provas tivessem sido comentadas pela professora durante as entrevistas, para validar o procedimento de análise.

\section{Análise das provas}

Para a análise das provas, procedeu-se, em primeiro lugar, à formação de quatro grupos de acordo com cada professora elaboradora. As questões das 40 provas foram numeradas em seqüência, totalizando

\footnotetext{
${ }^{3}$ Foram também utilizados como instrumentos de coleta de dados da pesquisa entrevistas com as professoras, com os alunos e com a equipe diretiva; cadernos dos alunos; diários de classe e planos trimestrais de ensino; o Projeto Pedagógico da Escola E e observações feitas durante o período da pesquisa.
} 
128 questões que foram analisadas de acordo com o conteúdo e quanto às técnicas de elaboração das questões. Posteriormente procedeu-se ao cruzamento desse dados para verificar a diversificação de técnicas com relação a conteúdos, estratégia importante para reduzir a interferência da técnica na testagem do conteúdo e para elevar o grau de confiabilidade de um instrumento de avaliação (ALDERSON et al., 1998; HUGHES, 1989).

\section{Análise quanto ao conteúdo}

O conteúdo ${ }^{4}$ foi determinado a partir das próprias provas, isto é, as questões foram classificadas de acordo com o objetivo de cada uma e nomeadas como questões de vocabulário; de gramática: morfologia, sintaxe, fonologia / grafia; e de habilidades: ler e escrever. Algumas questões foram classificadas como mistas, por testarem, ao mesmo tempo, mais de um conhecimento ou uma habilidade, simultânea ou sucessivamente.

\section{Análise quanto às técnicas}

Da mesma forma, as provas foram lidas e relidas para classificar as questões quanto às técnicas utilizadas. Foram encontrados dois grupos, de acordo com a proposta de Genesee e Upshur (1999): questões de resposta fechada (RF) e questões de respostas limitada (RL). Não foram encontradas questões de resposta aberta (RA).

Para a análise dos resultados foram também levados em consideração depoimentos das professoras, colhidos em entrevistas ou espontaneamente, em conversas informais.

\section{Discussão dos resultados}

A primeira parte da discussão apresenta a classificação das provas quanto ao conteúdo avaliado. As técnicas utilizadas para elaborar as questões constituem o segundo aspecto apresentado e discutido.

\footnotetext{
${ }^{4}$ O termo conteúdo é utilizado em sentido abrangente, que inclui aspectos gramaticais e as habilidades lingüísticas, conforme Genesee e Upshur (1999).
} 


\section{Resultados quanto ao conteúdo das provas}

Quanto ao conteúdo das provas, as questões foram classificadas em quatro grupos: vocabulário, gramática, habilidades lingüísticas e questões mistas (GRAF. 1).

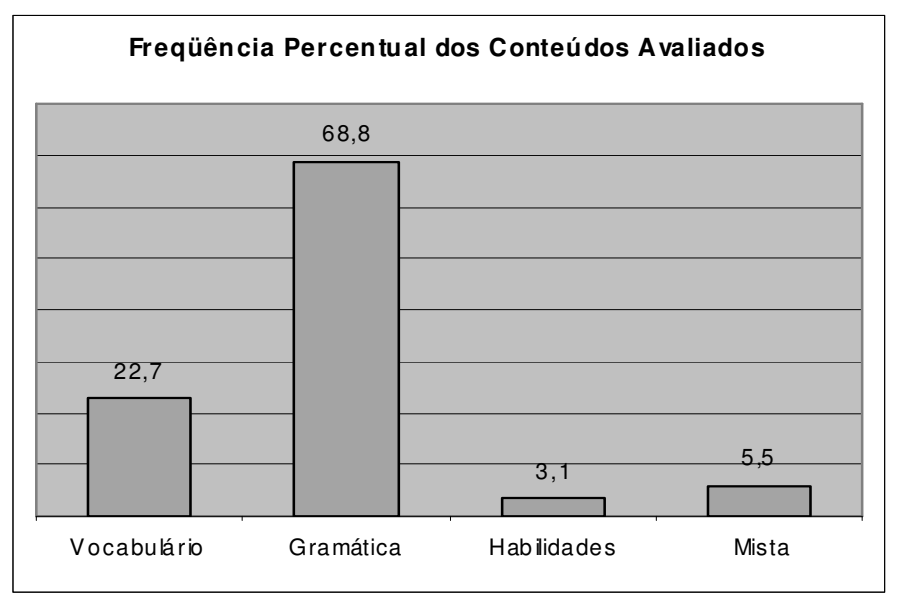

GRÁFICO 1 - Total percentual da freqüência dos conteúdos avaliados nas provas analisadas

A partir do GRAF. 1, pode-se perceber um desequilíbrio na distribuição dos conteúdos avaliados. As questões de gramática constituem a maior parte das provas, com $68,8 \%$ do total. As questões de vocabulário, com $22,7 \%$, são a segunda categoria mais freqüente. As questões sobre as habilidades lingüísticas significam apenas 3,1\%. As mistas representam 5,5\%. Portanto, há relação de desequilíbrio em favor do conteúdo gramatical e baixa incidência de questões visando a habilidades lingüísticas.

Analisando-se o grupo de questões de gramática detalhado no GRAF. 2, percebe-se um desequilíbrio também entre os conteúdos gramaticais avaliados: $73,5 \%$ das questões de gramática abrangem dois conteúdos apenas: verbo $(44,8 \%)$ e estrutura frasal $(28,7 \%)$. 


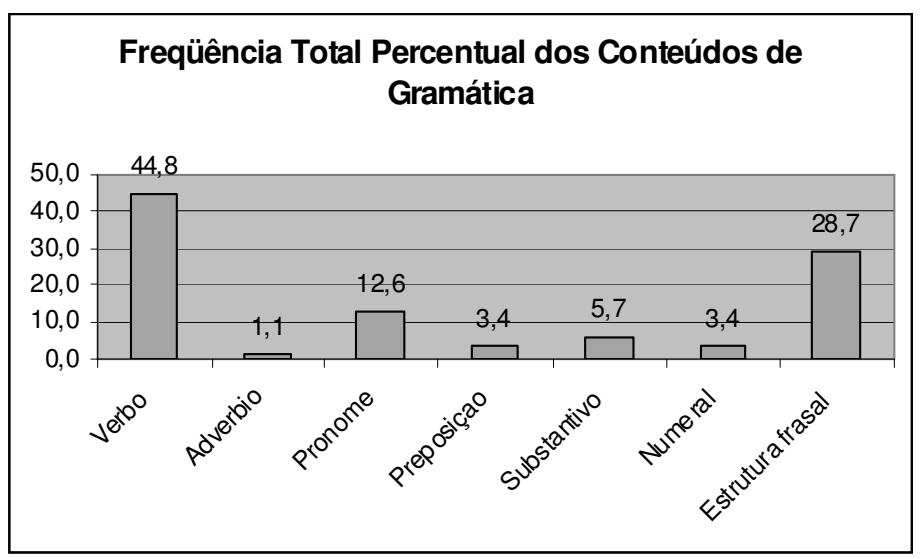

GRÁFICO 2- Freqüência percentual dos conteúdos de gramática

Percebe-se também, a partir do GRAF. 2, que nem todas as categorias gramaticais são testadas. A seleção de apenas algumas classes gramaticais, em especial o verbo, o substantivo e o pronome, pode ter justificativa à medida que a estrutura frasal trabalhada é a oração simples: S+V+C/A/O5 (QUIRK et al., 1972). Essas três classes são suficientes para formar orações simples, já que o substantivo $(5,7 \%)$ e pronome $(12,6 \%)$ são por excelência os formadores do sujeito e, com o verbo, constituem os elementos essenciais da oração simples. As demais classes avaliadas perfazem apenas 7,9\% do total. A partir desses dados, pode-se inferir que a seleção das classes gramaticais a serem estudadas é determinada por questões sintáticas, isto é, pela estrutura sintática em foco e não de forma aleatória.

Voltando aos dados do GRAF. 1, observa-se que as questões de vocabulário constituem a segunda categoria mais avaliada nas provas analisadas e caracterizam-se por apresentar, prioritariamente, palavras ou frases para traduzir ou versar, como no exemplo 1. Essas questões, como expõe Rivers (1975), aproximam-se da Abordagem Tradicional de Avaliação, de acordo com a qual o conhecimento lexical é avaliado através de listas de palavras e trechos de textos para traduzir e principalmente versar.

${ }^{5} \mathrm{~S}+\mathrm{V}+\mathrm{C} / \mathrm{A} / \mathrm{O}$, em que S significa Sujeito; V, verbo; C, complemento; A, adjunto adverbial e $\mathrm{O}$, objetos direto ou indireto. 
Exemplo 1 - Escreva em Inglês.
Lancheria -
Domingo -
Pátio -
Carta -
Cozinha -
Vovó -

Dentre as questões de habilidades lingüísticas (GRAF. 3), que perfazem apenas 3,9\% das questões analisadas, as de produção escrita constituem 60\% do total e as de compreensão escrita 40\%, conforme resultados no GRAF.

\section{GRÁFICO 3 - Freqüência Percentual das Habilidades Lingüísticas}

Dois aspectos podem ser discutidos a partir desse resultado: a inexistência de avaliação das habilidades orais e o predomínio da produção sobre a compreensão escrita. Ambos os aspectos podem ser atribuídos às condições de trabalho dos professores. A falta de material disponível para desenvolver as aulas pode ser definitivo para a baixa ocorrência de atividades orais dos objetivos de ensino e, em conseqüência, da avaliação, como ilustra a fala da professora Raquel: ${ }^{6}$

MT - ... quanto a tua condição de trabalho, tens condições de fazer um bom trabalho?

R - Olha, de material não. Nós não temos. Uma porque nossos alunos não têm condições ou a mesma coisa nós, professores.

\footnotetext{
${ }^{6}$ Os nomes das professoras são fictícios, sugeridos por elas mesmas.
} 
Eu sinto... tem que optar comer ou comprar o material didático. Claro que eu escolho a minha família. Aí eu vou indo assim, pedindo aqui, pedindo ali ... (Raquel)

Os registros nos diários de classe, no entanto, incluem trabalhos orais, ainda que em número reduzido, o que permite pensar que outros fatores podem limitar a avaliação da habilidade oral. Uma razão pode ser a priorização da habilidade escrita pelas professoras, expressa por Verônica ao justificar a suspensão de aulas de conversação: "a parte da fala dava certo, a parte da escrita era uma briga. Eles sabiam falar e não sabiam escrever (...) eles TÊM que saber ler e escrever (...)". Outra razão, ainda, pode ser a dificuldade de avaliar a habilidade oral, como afirmam as professoras Raquel e Camila, constatando que o mais difícil de avaliar em inglês é a pronúncia.

A menor incidência de exercícios de compreensão de leitura poderia ser devido à dificuldade de reprodução de material: "(...) xerox não tem como usar porque não se pode pedir dinheiro para os alunos e, mesmo que pudesse eles não têm pra dar (...) se eu dou xerox sou eu que pago (...) a gente trabalha com matrizes (...)" (Camila).

Algumas falas, no entanto, deixam perceber outras razões para isso, como no caso da professora Lya e da professora Verônica, que não trabalham compreensão de leitura por convicção, por acreditarem que o texto deve ser utilizado para exercitar tradução ou vocabulário.

Gosto de trabalhar muito com texto. Texto para ser TRADUZIDO. Não para trabalhar com... pedir a interpretação do texto. Tudo bem, a interpretação, posso até fazer, até faço. (Lya)

O meu objetivo com o texto é para ampliar o vocabulário deles, né? Pra eles terem noção, verem o conteúdo deles dentro do texto. Assim como em português também fazem (...) (Verônica)

\section{Resultados quanto às técnicas utilizadas}

Na seqüência, as provas foram avaliadas pelo tipo de técnica empregada para elaborar as questões. Das 128 questões, 82,8\% são de questões de resposta limitada, 13,3\% representam as questões de resposta fechada e 3,9\% são respostas mistas. O GRAF. 4 apresenta esses resultados. 
GRÁFICO 4 - Total percentual quanto às técnicas utilizadas pelas professoras

Os dados no GRAF. 4 mostram que há preferência pelas técnicas de resposta limitada. As técnicas de resposta fechada, no entanto, totalizando 13,3\%, representam um índice não desprezível, considerandose que representam questões que não permitem ao professor detectar a origem dos erros. Esse resultado possui diferenças mais acentuadas que o encontrado por Santos (2002) em provas elaboradas por estagiários: 69\% de resposta limitada e 31\% de resposta fechada. Dentre as técnicas de resposta limitada, as técnicas de lacuna, transformação, versão e escreva são as mais utilizadas (GRAF. 5).

GRÁFICO 5 - Freqüência total das técnicas utilizadas nas provas avaliadas 
As técnicas preferidas nas provas analisadas neste estudo são a lacuna e a transformação. As questões de lacuna são utilizadas para testar aspectos gramaticais, focando essencialmente os verbos na forma de drills que, predominantemente, podem ser respondidas sem que haja a compreensão de sentido, como no exemplo 2.

Exemplo 2 - Complete as frases usando os verbos no simple present. breakfast at six thirty in the morning. (to have)

2. They milk every day. (drink)

A segunda técnica mais freqüente é a transformação, exercício interessante para testar estrutura gramatical de acordo com um padrão (pattern). Lado (1961, p. 169) recomenda esse tipo de técnica para testar estruturas como as formas negativas e interrogativas.

Exemplos das provas avaliadas mostram o uso de questões de transformação para verificar apenas a estrutura gramatical simples $(\mathrm{S}+\mathrm{V}+\mathrm{O}+\mathrm{C})$, muitas vezes sem a necessidade de compreensão do sentido para efetuar as transformações, como se observa no exemplo 3.

Exemplo 3 - Escreva os verbos a seguir no imperativo afirmativo e negativo:

5. to turn right.

6. to sing in class.

Torne as frases abaixo interrogativas:

1. Paul meets me at the club every Sunday.

2. I speak English well.

Passe as frases para a terceira pessoa:

a. The teachers teach English.

b. They touch the fruit at the market.

Use the Genitive Case:

1 - The dog of my borther.

2 - The trousers of my sister-in-law.

Tanto Baxter (1997, p. 41) como Hughes (1989, p. 143) percebem a técnica de transformação como integrativa, ideal para avaliar os níveis intermediário e avançado. Para esses autores, a técnica de transformação é indicada para verificar conhecimentos estruturais mais complexos, como reported speech, too/enough, modais, passivas, que requerem 
alguma compreensão da frase para resolver o exercício. Nas provas analisadas, não ocorre nenhuma dessas estruturas. A técnica de transformação é utilizada para situações do tipo: alterar frases para as formas negativa e interrogativa, do indicativo para o imperativo, do singular para o plural. A limitação de uso dessa técnica a níveis iniciais é conseqüência do ensino que, por sua vez, permanece nesse nível pela falta de domínio lingüístico do professor, como expressa a professora Lya:

$\mathrm{MT}^{7}$ - O que é mais difícil de aprender em inglês? O que é mais importante tu disseste: vocabulário. E o que é mais difícil?

L - $\quad$ A gramática. Quando entra na questão de... mais ampla: voz passiva, discurso direto e indireto, uso de modais, essa é a parte mais difícil da língua inglesa, a gramática, mas dessa parte secundária... Porque as outras partes da gramática são memorização. Por exemplo, se tu vais fazer um presente contínuo, um presente progressivo, você sabe que tem que usar um sujeito, o verbo to be no presente - que a gente aprendeu desde que a gente começou a aprender inglês - mais o verbo no ing, que é a nossa formulazinha. Então, é uma questão de memorização. Só que o discurso direto e indireto, a voz passiva tem que pensar BEM mais. ... É a parte que eu acho mais difícil da língua inglesa é a gramática, essa gramática da voz passiva, do discurso direto e indireto e o uso de modais.

Assim, o uso pleno de uma técnica pode ser limitado por deficiência lingüística do professor.

A tradução/versão, como "quinta habilidade lingüística" (LADO, 1961), é exercício complexo que requer não só domínio lingüísticocomunicativo, como um sólido conhecimento cultural de ambas as línguas. Já como técnica de avaliação, está associada a uma prática tradicional que privilegia o conhecimento lexical e gramatical. É exatamente nesse sentido que essa técnica é utilizada nas provas analisadas.

O grupo de técnicas de RL menos utilizadas inclui edição $(0,8 \%)$, ordenação $(1,6 \%)$, responda $(1,6 \%)$ e ditado $(1,6 \%)$. As questões de edição, ordenação e responda, embora relativamente fáceis de elaborar,

\footnotetext{
7 As transcrições de diálogos tem as falas identificadas com a iniciais MT para Maria Tereza e C para Camila, L para Lya, R para Raquel e V para Verônica.
} 
apresentam maior dificuldade de correção, exigem um bom domínio da língua pelo professor para julgar as respostas. São questões que dão margem à produção de um tipo de erro que, mesmo em nível básico, requer explicações sobre relações sintáticas, assunto possivelmente tomado como mais complexo que as regras morfológicas. O ditado (1,6\%) é uma técnica pouco freqüente em provas porque, de modo geral, constitui trabalhos isolados ao longo dos trimestres, de acordo com registros nos cadernos dos alunos.

Quanto às questões de resposta fechada, destaca-se a múltipla escolha, com 10,2\% (GRAF. 5). Uma explicação para essa preferência por ME pode ser porque essas questões são mais fáceis de elaborar para níveis iniciais (ALDERSON et al., 1998); no entanto, trazem consigo a desvantagem de não permitir precisar se o acerto (ou o erro) foi conseqüência de tentativa do aluno que não sabia a resposta ou do que dominava o conteúdo, o que dificulta o retorno que o professor deve dar ao seu aluno. Se a maioria acerta, ainda assim o professor não pode afirmar com segurança que pode passar adiante porque houve aprendizagem, uma vez que os acertos podem ser atribuídos ao acaso.

As questões com menor freqüência são de V/F e associação. Essa menor incidência talvez seja porque as questões de $\mathrm{V} / \mathrm{F}$ são difíceis de redigir para testar itens isolados. Já as questões de associação, não apresentam muita dificuldade de elaboração, mas demandam tempo para a seleção dos elementos que constituem os conjuntos. As questões de julgamento são pouco exploradas, possivelmente por parecerem fáceis de resolver, uma vez que o aluno deve escolher entre duas respostas apenas. De acordo com Hughes (1989), são questões que dão muita chance ao aluno de acertar sem saber, o que não condiz com o propósito de "fazer eles pensarem" (Verônica).

\section{Análise da freqüência do conteúdo com relação às técnicas}

A análise quanto ao conteúdo $\mathrm{x}$ técnica visa verificar tanto a freqüência de uso de uma mesma técnica para um mesmo conteúdo quanto o uso de uma técnica para diferentes conteúdos. A importância de cruzar essas informações é discutida por Alderson et al. (1998) e Hughes (1989), que argumentam a favor da diversificação de técnicas, isto é, um mesmo conteúdo deve ser avaliado por mais de uma técnica. 
Esse procedimento objetiva reduzir a interferência da técnica na testagem do conteúdo, elevando o grau de confiabilidade de um instrumento de avaliação. Esses autores alertam que avaliar um conteúdo através de uma mesma técnica, potencialmente, "mascara" o resultado, uma vez que o aluno pode "estudar" para melhorar seu desempenho na técnica repetida pelo professor, em lugar de estudar o conteúdo. A TAB. 1 representa os resultados dessa relação.

TABELA 1

Resultados percentuais relativos às técnicas utilizadas e conteúdos avaliados

A partir dos dados da TAB. 1, observa-se que vocabulário e verbo são testados por seis técnicas diferentes cada um: lacuna, associação, escreva, versão, tradução e ditado. Essa diversificação está de acordo com Genesee e Upshur (1999) e Bachman (1990), que alertam sobre a necessidade de atentar para que a(s) característica(s) da técnica não seja $(m)$ incompatível(eis) com a habilidade a ser avaliada, o que pode ser compensado com a diversificação de técnicas.

Há ênfase, no entanto, nas técnicas de tradução $(7,8 \%)$ e versão (7,8\%), para testar vocabulário, e lacuna (16,4\%), técnica utilizada para testar verbos. Os demais conteúdos com maior freqüência parecem diretamente relacionados a determinadas técnicas: estrutura frasal é conteúdo avaliado, sobretudo, por questões de transformação; e os pronomes, embora relacionados com três técnicas diferentes, apresentam forte ligação com as questões de ME.

A tradução de palavras ou frases feitas para exercitar vocabulário, como predomina nas provas, é uma técnica que envolve reconhecimento apenas (exemplo 4), não exige produção nem permite que o aluno dê 
uma resposta mais elaborada. Read (2000) lembra que testar vocabulário apenas através da língua materna, tradução ou versão, pode levar o aluno a consolidar a idéia de que há uma correspondência exata entre as palavras nas duas línguas.

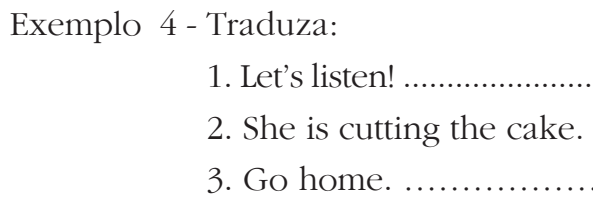

Nesse caso, o professor fornece ao aluno o estímulo (forma em inglês) para que ele resgate na memória o elemento correspondente (forma em português). Outros tipos de técnicas devem ser também utilizados para que as diferenças possam ser percebidas. No entanto, isso não ocorreu nas provas analisadas, uma vez que as demais técnicas foram pouco utilizadas.

Escreva (15,6\%) é a técnica mais repetida. Testa cinco conteúdos diferentes, com relativa uniformidade na distribuição. Essa técnica apresenta vantagens na avaliação de competência lingüística e, quando restrita à competência gramatical, é de fácil elaboração e correção (BACHMAN, 1990, p. 84). No caso das provas avaliadas, apenas 10,2\% das questões de Escreva não são sobre gramática, o que pode sugerir que essa técnica foi mais explorada pela vantagem da facilidade que apresenta ao professor.

As questões de múltipla escolha (14,1\%) são utilizadas para testar gramática: pronome e verbo. Possivelmente isso se explique porque as questões de ME para níveis iniciais são mais fáceis de elaborar. São também mais fáceis de elaborar questões de ME sobre conteúdo gramatical do que sobre questões de compreensão (ALDERSON et al., 1998). Observa-se que as questões de compreensão de leitura nas provas são em número reduzido e envolvem outras técnicas também de resposta limitada - V/F e associação. Por sua vez, as questões de transformação $(21,9 \%)$ são em maior número e, pela própria natureza da técnica, concentram-se na avaliação de estrutura frasal (10,2\%).

É necessário destacar, no entanto, que se a desuniformidade na distribuição de técnicas não representa por si só problemas (GENESEE; UPSHUR, 1999; BACHMAN, 1990), como nas provas analisadas, a avaliação de conteúdos por uma única técnica não caracteriza um 
procedimento avaliativo adequado porque se o aluno não tem bom desempenho na habilidade que a técnica testa, poderá ser prejudicado (ALDERSON et al., 1998). Quanto a esse aspecto, as provas estudadas não têm boa diversificação na relação conteúdos x técnicas.

No que se refere à ocorrência de erros lingüísticos na elaboração das provas, diferentemente do que encontra Santos (2002), as provas avaliadas não apresentam "erros de língua". Falando sobre como elaboram as provas, as professoras revelaram que "copiam" dos livros, isto é, as frases (e textos) que devem estar em inglês são transcritas de manuais e (re)agrupadas de acordo com o objetivo da questão que estão construindo. Assim, alguns erros encontrados foram atribuídos a descuido e pressa na hora de redigir as questões nas matrizes (exemplo 5) ou erros propositais, como alternativas em questões de ME (exemplo 6).

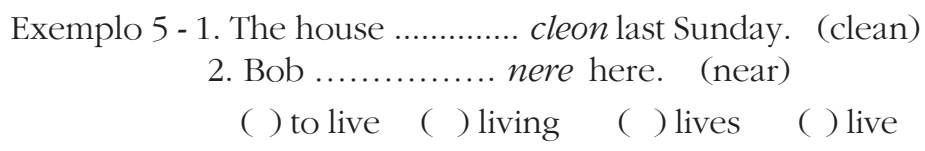

Exemplo $6-1$. We usually late.
a. getes up
b. gets up
c. get up

2. Liz and I are Football.
a. playing
b. play
c. plaing

\section{Conclusões}

Os resultados discutidos permitem concluir que quanto aos conteúdos avaliados, o foco das provas concentra-se predominantemente em itens gramaticais das classes que constituem a oração simples, na estrutura da oração simples e no vocabulário, orientação que pode ser resultado do pouco domínio lingüístico dos professores.

Quanto ao tipo de técnica utilizada pelas professoras, há o predomínio de técnicas de resposta limitada: questões de fácil elaboração e, sobretudo, de fácil correção, que exigem pouco conhecimento lingüístico do professor, da mesma forma que pouco conhecimento das próprias técnicas para elaboração de questões.

No que se refere à relação entre técnicas e conteúdo, as provas não apresentam diversificação uniforme na exploração dos conteúdos por 
várias técnicas. Os conteúdos explorados pelo maior número de técnicas são justamente aqueles a que as professoras atribuem maior importância e que apresentam maior freqüência. Ainda assim, há estreita relação entre tradução/versão com vocabulário, e lacunas com verbos. Com isso, percebe-se o objetivo de que o aluno adquira estruturas sem desenvolver habilidades comunicativas. Pode-se entender ainda que os resultados indicam uma relação que privilegia a objetividade, relação manifestada pela unicidade de resposta para cada questão.

As conclusões apontam para a necessidade de se reverem, nos cursos de formação de professores da Região Sul, a preparação para a avaliação e o desenvolvimento da fluência em língua estrangeira, quer em estágio de formação inicial quer em estágio posterior, de formação permanente.

\section{Referências Bibliográficas}

ALDERSON, Charles; CLAPHAN, Caroline; WALL, Diane. Exámenes de Idiomas. Elaboración y evaluación. Cambridge: University Press, 1998.

BACHMAN, Lyle F. Fundamental considerations in language testing. Oxford: Oxford University Press, 1990.

BAILEY, Kathleen. Learning About Language Assessment: Dilemmas, Decisions, and Directions. New York: Newbury House, 1998.

BAXTER, A. Evaluating your Students. London: Richmond, 1997.

GENESEE, Fred; UPSHUR, John. Classroom-Based Evaluation in Second Language Education. Cambridge: Cambridge University Press, 1999.

HOFfman, Jussara. Avaliação Mediadora. Porto Alegre: Educação \& Realidade, 1993.

HUGHES, G. Testing for Language Teachers. Cambridge: Cambridge University Press, 1989.

INSTITUTO BRASILEIRO DE GEOGRAFIA E ESTATÍSTICA (IBGE). Indicadores sociais municipais. Disponível em $<$ http://www.ibge.gov.br/home/estatistica/ populacao/indicadores sociais municipais/>. Acesso em: 19 Abr. 2004.

LADO, Robert. Language Testing. New York: McGraw-Hill, 1961.

LINDEMAN, Richard. Medidas educacionais. Porto Alegre: Globo, 1975. 
LUCKESI, Cipriano C. Avaliação da aprendizagem escolar. 4. ed. São Paulo: Cortez, 1996.

MEDEIROS, Ethel Bauzer. As provas objetivas: técnicas de construção. Rio de Janeiro: Fundação Getúlio Vargas, Ser. De publicações, 1971.

QUIRK, R.; GREENBAUM, S.; LEECH, G; SVARTVIK, J. A. A grammar of contemporary English. London: Longman, 1972.

READ, John. Assessing Vocabulary. Cambridge: Cambridge University Press, 2000.

RIVERS, Wilga. A metodologia do ensino de linguas estrangeiras. São Paulo: Pioneira, 1975.

ROLIM, A. Ana Cláudia O. A cultura de avaliar de professoras de lingua estrangeira (inglês) no contexto da escola pública. 1998. Dissertação (Mestrado em Lingüística Aplicada) - Unicamp, Campinas, SP.

SANTOS, Laura L.F. Análise de Provas Elaboradas por Professores em Formação: Um estudo de Caso. 2002. Dissertação (Mestrado em Lingüística Aplicada) - Faculdade de Letras da UFMG, Belo Horizonte.

VASCONCELOS, Celso. Avaliação da aprendizagem: práticas de mudança por uma práxis transformadora. 5. ed. São Paulo: Libertad, 2003. 